\title{
KARAKTERISTIK PERMEN JELLY DENGAN PENAMBAHAN IOTA KARAGENAN DARI RUMPUT LAUT Eucheuma spinosum
}

\author{
The Characteristics of Jelly Candy with Addition of Iota Carrageenan \\ from Seaweed Eucheuma spinosum
}

\author{
Mukarima Rismandari, Tri Winarni Agustini dan Ulfah Amalia \\ Program Studi Teknologi Hasil Perikanan \\ Fakultas Perikanan dan Ilmu Kelautan, Universitas Diponegoro \\ J1. Prof. Soedarto, SH, Tembalang, Semarang, Jawa Tengah - 50275, Telp/fax. +6224 747698 \\ Email: ndari1994@gmail,.com
}

Diserahkan tanggal 2 Desember 2016, Diterima tanggal 11 Januari 2017

\begin{abstract}
ABSTRAK
Permen jelly merupakan permen yang memiliki tekstur kenyal. Tekstur ini terbentuk karena adanya pembentuk gel yaitu gelatin. Penggunaan gelatin dalam permen jelly masih diperdebatkan status kehalalannya, karena adanya unsur babi dalam gelatin. Sementara itu, sumber alternatif lain yang memberikan tekstur kenyal di permen jelly adalah karagenan, tetapi belum jelas sejauh mana dapat menggantikan gelatin. Tujuan dari penelitian ini adalah mengetahui pengaruh iota karagenan yang diekstrak dari Eucheuma spinosum terhadap sifat fisik dan kimia permen jelly dan formulasi terbaik dari permen jelly. Bahan yang digunakan dalam penelitian ini adalah gelatin dan tepung iota karagenan yang diekstrak dari rumput laut E. spinosum. Metode penelitian yang digunakan yaitu experimental laboratories dengan desain percobaan rancangan acak lengkap (RAL) dengan 4 perlakuan yang berbeda yaitu Gelatin : Iota Karagenan $=8 \%: 0 \%$ (A), Gelatin : Iota Karagenan $=0 \%: 8 \%$ (B ), Gelatin : Iota Karagenan $=6 \%: 2 \%(C)$, dan Gelatin : Iota Karagenan $=2 \%: 6 \%$ (D). Hasil dari penelitian ini didapatkan permen jelly terbaik sebagai alternatif pengganti gelatin yaitu perlakuan B dengan kekuatan gel 1.109,27 g. $\mathrm{cm}^{2}$ dan nilai hedonik sebesar 6,84 $\leq \mu \leq 7,52$. Kadar air semua perlakuan belum memenuhi standar SNI (20\%). Kadar abu semua perlakuan memenuhi standar SNI (3\%). Untuk $\mathrm{a}_{\mathrm{w}}$ dan pH produk tersebut berkisar $0,84-0,89$ dan 3-4 .
\end{abstract}

Kata kunci: Gelatin, Eucheuma spinosum, Tepung Iota Karagenan, Permen Jelly

\section{ABSTRACT}

Jelly candy which has chewy texture. This texture was formed by the gelling agent of gelatin. The use of gelatin in jelly candy still debated of halal status, because there were elements of pork in gelatin. While other alternative source which gives chewy texture in jelly candy was carrageenan, but carrageenan were used in making jelly candy was not extent to be replace of gelatin. The aim of this study was to determine the effect of iota carrageenan extracted from Eucheuma spinosum to physical and chemical characteristics of jelly candy and the best formulation of jelly candy. The materials used in the research were gelatin and powder of iota carrageenan extracted from seaweed E. spinosum. The method used was experimental laboratories by using completely randomized design (CRD) with 4 different treatments was Gelatin : Iota carrageenan $=8 \%: 0 \%($ A), Gelatin : Iota carrageenan $=0 \%: 8 \%(B)$, Gelatin : Iota carrageenan $=6 \%: 2 \%(C)$, and Gelatin : Iota carrageenan $=2 \%: 6 \%(D)$. The result showed that the best jelly candy as an alternative to gelatin performed by treatment $B$ with gel strength of 1109,27 g. $\mathrm{cm}^{2}$ and the results for sensory was $6,84 \leq \mu \leq 7,52$. The water content of all treatment did not comply with ISO standard (20\%). Ash content of all treatment comply with ISO standard (3 $\%)$. For $a_{w}$ and $\mathrm{pH}$ of the products were ranged from 0.84-0.89 and 3-4, respectively.

Keywords: Gelatin, Eucheuma spinosum, Iota Carrageenan Powder, Jelly Candy

\section{PENDAHULUAN}

Permen adalah sejenis gula-gula (confectionary) yang banyak disukai oleh anak-anak hingga dewasa. Permen yang banyak beredar di pasaran sangat beragam bentuk, jenis, maupun rasanya, antara lain permen karet (gum), permen lolipop, permen kenyal (jelly), permen keras (hard candy), permen berbahan dasar coklat (bounty), caramel, caramel kacang kunyah, nougat, dan permen jahe (Yustina dan Antarlina, 2013).

Badan Standarasisai Nasional (2008) mengemukakan bahwa permen jelly adalah kembang gula bertekstur lunak, yang diproses dengan penambahan komponen hidrokoloid seperti agar, gum, pektin, pati, karagenan, gelatin dan lain-lain 
yang digunakan untuk modifikasi tekstur sehingga menghasilkan produk yang kenyal. Dominasi gelatin sebagai salah satu komponen hidrokoloid pembentuk permen jelly sebanyak $23 \%$ dari penggunaan gelatin dalam industri pangan sebesar 154,000 ton (Hastuti dan Sumpe, 2007).

Gelatin merupakan biopolimer yang digunakan dalam makanan, farmasi, dan aplikasi foto karena sifat fungsional yang dimilikinya. Umumnya sumber utama gelatin adalah tulang dan kulit dari babi dan sapi. Data terbaru menunjukkan bahwa produksi gelatin di dunia mencapai 326,000 ton/tahun, gelatin yang berasal dari kulit babi menempati produksi tertinggi (46\%), diikuti oleh kulit sapi $(29,4 \%)$, tulang sapi $(23,1 \%)$, dan sumber-sumber lain (1,5\%) (Suptijah et al., 2013).

Pada umumnya permen jelly dibuat dengan gelatin sebagai bahan pembentuk gel. Selama ini bahan gelatin komersial sebagian besar masih diimpor dari Eropa dan Amerika. Selain harganya yang relatif tinggi, gelatin impor sering diragukan kehalalannya bagi kaum muslim karena diduga mengandung unsur babi. Keunggulan lain menggunakan gelatin babi dari pada sumber yang lain dikarenakan sifat fisika dan viskositasnya yang tinggi dari pada gelatin sumber lain. Selain penggunaan gelatin dalam pembuatan permen jelly, sudah dilakukan penelitian untuk menggantikan gelatin sebagai gelling agent dalam pembuatan permen jelly. Salah satunya dengan menggunakan karagenan, tetapi belum diketahui sejauh mana dapat menggantikan penggunaan gelatin.

\section{METODE PENELITIAN}

\section{Materi Penelitian \\ Bahan baku yang digunakan dalam penelitian ini adalah rumput laut Eucheuma spinosum sebagai bahan utama pembuatan iota karagenan. Bahan lainnya yang digunakan adalah $\mathrm{NaOH} 8 \%$, larutan IPA, aquades, gelatin, sukrosa, HFS, air, flavor, asam sitrat, natrium benzoat. Alat-alat yang digunakan antara lain baskom, gelas ukur, sendok pengaduk, kain blancu, panci, kompor gas, oven, sodet, termometer, timbangan, loyang, sendok stainless steel, pisau. Alat-alat yang digunakan untuk analisis adalah alat-alat gelas (gelas piala, gelas ukur, labu takar, pengaduk gelas, erlenmeyer, corong), texture analyzer, cawan porselen, tanur, hot plate, water bath, dan oven}

\section{Metode Penelitian \\ Penelitian Tahap I}

Penelitian Tahap I adalah ekstraksi iota karagenan dari rumput laut Eucheuma spinosum. Rumput laut diekstraksi menurut metoda Darmawan et al. (2014) yang telah dimodifikasi. Rumput laut yang telah kering dicuci bersih dan diektraksi I menggunakan larutan alkali dengan suhu ekstraksi dihitung setelah suhu larutan mencapai $90-95^{\circ} \mathrm{C}$ selama 2 jam. Rumput laut dicuci bersih dan diekstraksi II. Setelah proses ekstraksi selesai, dilakukan proses penyaringan. Sebelum disaring ditambahkan cellite dengan konsentrasi $2 \%(\mathrm{~b} / \mathrm{v}) \mathrm{ke}$ dalam rumput laut yang sedang diekstrak dan diaduk-aduk selanjutnya dilakukan penyaringan saring dalam keadaan panas. Selanjut dilakukan presipitasi dengan IPA dengan perbandingan (filtrat : IPA 1:2). Selanutnya dikeringkan kemudian digiling sehingga diperoleh tepung iota karagenan.

Rendemen karagenan dihitung berdasarkan rasio berat karagenan kering yang dihasilkan dengan berat rumput laut kering. Kadar sulfat dianalisis menurut metode SNI (2004). Kekuatan gel dianalisis menggunakan texture analyzer.

\section{Penelitian Tahap II}

Penelitian Tahap II dilakukan dengan penambahan tepung ekstraksi iota karagenan terpilih pada penelitian tahap I kedalam formulasi permen jelly mengacu pada penelitian Rahmawati et al. (2015) dengan modifikasi dengan penelitian Sinurat dan Murniyati (2014). Pelarutan masing-masing formulasi pada wadah berbeda. Penambahan sukrosa dan high fructose syrup (HFS) dalam air sambil dipanaskan hingga larut. Pemanasan dilakukan dalam waktu kurang lebih 5 menit. Pencampuran masing-masing formulasi kedalam larutan gula dengan penambahan asam sitrat, natrium benzoat, flavor hingga adonan tercampur rata dimasak hingga $80-90^{\circ} \mathrm{C}$ bertujuan agar terbentuk gel akibat proses pemasakan. Penuangan kedalam cetakan lalu dipotong kemudian dikemas.

Tabel 1. Komposisi bahan yang digunakan pada pembuatan permen jelly dalam $100 \mathrm{~g}$

\begin{tabular}{lcccc}
\hline \multirow{1}{*}{\multicolumn{1}{c}{ Bahan }} & \multicolumn{4}{c}{ Perlakuan } \\
\cline { 2 - 5 } & A & B & C & D \\
\cline { 2 - 5 } & \% & \% & \% & \% \\
\hline Gelatin & 8 & 0 & 6 & 2 \\
Iota Karagenan & 0 & 8 & 2 & 6 \\
Sukrosa & 48,78 & 48,78 & 48,78 & 48,78 \\
HFS & 12 & 12 & 12 & 12 \\
Asam Sitrat & 0,8 & 0,8 & 0,8 & 0,8 \\
Natrium Benzoat & 0,15 & 0,15 & 0,15 & 0,15 \\
Flavor & 1,6 & 1,6 & 1,6 & 1,6 \\
Air & 12 & 12 & 12 & 12 \\
\hline Total & 100 & 100 & 100 & 100 \\
\hline
\end{tabular}

\section{Parameter Pengujian}

Pengujian untuk permen jelly penelitian meliputi uji fisik, kimia dan mikrobiologi. Uji fisik meliputi Gel Strength (Shimizu et al., 1992), kadar air metode oven (BSN, 2008), uji kadar abu (BSN, 2008). Uji kimia meliputi pH (Hadiwiyoto, 1994 dalam Maitimu et al. 2012) dan $\mathrm{a}_{\mathrm{w}}$ (AOAC 925.45, 1999), sedangan pengujian mikrobiologi yaitu kapang (BSN, 2008).

\section{Rancangan Percobaan}

Rancangan percobaan yang digunakan dalam penelitian ini adalah Rancangan Acak Lengkap (RAL) dengan 4 perlakuan yang berbeda yaitu Gelatin : Iota Karagenan $=8 \%$ : $0 \%$ (A), Gelatin : Iota Karagenan $=0 \%: 8 \%$ (B ), Gelatin : Iota Karagenan $=6 \%: 2 \%(\mathrm{C})$, dan Gelatin : Iota Karagenan $=$ 2\%: $6 \%$ (D). Pengujian normalitas dan homogenitas dilakukan terlebih dahulu sebelum analisa ANOVA, agar dapat diketahui sifat data sehingga dapat dilakukan sidik ragam atau tidak. Metode analisa yang digunakan adalah sidik ragam ANOVA dengan uji lanjut untuk menentukan nilai yang berpengaruh maupun yang tidak dengan Uji BNJ (Beda Nyata Jujur). 


\section{HASIL DAN PEMBAHASAN}

\section{Penelitian Tahap I}

Berikut ini merupakan hasil dari penelitian Tahap I: Tabel 2. Karakteristik tepung iota karagenan

\begin{tabular}{lcc}
\hline \multirow{2}{*}{ Sifat Fisik } & \multicolumn{2}{c}{ Larutan Alkali } \\
\cline { 2 - 3 } & $\mathbf{N a O H}$ & $\mathbf{C a}(\mathbf{O H})_{2}$ \\
\hline Rendemen $(\%)$ & 7,2 & 5,5 \\
Kadar sulfat $(\%)$ & 19,27 & 0,26 \\
Gel strength $\left(\mathrm{g} . \mathrm{cm}^{2}\right)$ & 69,32 & 53,05 \\
\hline
\end{tabular}

Rendemen larutan alkali $\mathrm{NaOH}$ sebesar 7,2 \% dan rendemen larutan alkali $\mathrm{Ca}(\mathrm{OH})_{2}$ sebesar $5,5 \%$. Nilai rata-rata rendemen iota karagenan yang dihasilkan lebih rendah dibandingkan dengan nilai rata-rata rendemen karagenan yang didapatkan oleh Darmawan et al. (2014) yaitu 14,23\%. Nilai rata-rata rendemen penelitian ini juga lebih rendah dari pada Yasita dan Rachmawati (2009) yaitu 11,40-39,71\%. Hal ini dipengaruhi oleh jenis pengendap terhadap rendemen karagenan yang dihasilkan, dimana pada penelitian ini jenis pengendap yang digunakan adalah Isopropyl Alkohol (IPA). Menurut Yasita dan Rachmawati (2009), rendemen yang dihasilkan dengan pengendap jenis etanol lebih besar dibanding pengendap jenis Isopropyl Alkohol (IPA). Hal ini disebabkan karena etanol memiliki rantai carbon (C) lebih pendek (2) dibandingkan Isopropyl alkohol yang memiliki rantai $\mathrm{C}$ berjumlah 3 , yang artinya etanol lebih baik dalam mengestrak rumput laut dan menghasilkan rendemen yang besar.

Kadar sulfat larutan alkali $\mathrm{NaOH}$ sebesar $19,27 \%$ dan kadar sulfat larutan alkali $\mathrm{Ca}(\mathrm{OH})_{2}$ sebesar $0,26 \%$. Standar kadar Sulfat menurut FAO dalam Diharmi et al. (2011) untuk iota karagenan yaitu $14-40 \%$, sedangkan kadar sulfat dari tepung iota karagenan yang masuk dalam kriteria tersebut adalah tepung iota karagenan dari ekstraksi rumput laut Eucheuma. spinosum dengan menggunakan larutan alkali $\mathrm{NaOH}$ sebesar 19,27 \%. Hasil ekstraksi rumput laut biasanya dibedakan menurut kandungan sulfatnya. Agar mengandung sulfat $3-4 \%$ sedangkan karagenan minimal kandungan sulfatnya $18 \%$.

Gel strength tepung iota karagenan dari larutan alkali $\mathrm{NaOH}$ sebesar $69,32 \%$ dan gel strength tepung iota karagenan dari larutan alkali $\mathrm{Ca}(\mathrm{OH})_{2}$ sebesar 53,05 \%. Standar gel strength menurut FAO dalam Asikin et al. (2015) untuk karagenan yaitu $20-500 \mathrm{~g} / \mathrm{cm}^{2}$, sehingga untuk nilai rata-rata nilai gel strength iota karagenan untuk dua perlakuan $\mathrm{NaOH}$ dan $\mathrm{Ca}(\mathrm{OH})_{2}$ masuk dalam kriteria FAO.

Berdasarkan penilaian terhadap tepung iota karagenan hasil penelitian, didapatkan untuk hasil rendemen yang dipilih yaitu tepung dari alkali $\mathrm{NaOH}$. Kadar sulfat yang masuk dalam kriteria FAO yaitu tepung karagenan dari alkali $\mathrm{NaOH}$, sedangkan untuk gel strength diambil nilai yang tertinggi yaitu gel strength dari alkali $\mathrm{NaOH}$.

\section{Penelitian Tahap II}

Kadar air

Tabel 3. Kadar Air Permen Jelly Hasil Penelitian

\begin{tabular}{cc}
\hline Perlakuan & Kadar Air \\
\hline A (Gelatin 8\% : Iota K. 0\%) & $31,10 \pm 0,68^{\mathrm{a}}$ \\
B (Gelatin 0\% : Iota K. 8\%) & $38,95 \pm 0,65^{\mathrm{b}}$ \\
C (Gelatin 6\% : Iota K. 2\%) & $48,18 \pm 0,15^{\mathrm{c}}$ \\
D (Gelatin 2\% : Iota K. 6\%) & $46,46 \pm 0,44^{\mathrm{d}}$ \\
\hline
\end{tabular}

Kadar air permen jelly hasil penelitian ini $50 \%$ lebih tinggi dari kadar air tertinggi permen jelly hasil penelitian Sinurat dan Murniyati (2014) yang sebesar 28,3\%. Menurut Mahardika et al. (2014), kadar air sangat berpengaruh dalam mutu pangan sehingga dalam pengolahan, air tersebut sering dikeluarkan atau dikurangi dengan cara penguapan dan pengeringan. Menurut Rahmi et al. (2012), tingginya kadar air yang dihasilkan pada permen jelly disebabkan karena substansi pada bahan terlalu banyak mengandung air atau padatan terlarutnya terlalu rendah sehingga konsistensinya tidak begitu kuat. Konsistensi pembentuk gel yang terlalu sedikit menyebabkan jaringan tidak kuat menahan cairan gula sehingga menyebabkan permen mengalami sineresis dan menghasilkan kadar air yang tinggi.

Menurut Atmaka et al. (2013), pembentuk gel adalah suatu fenomena atau pengikatan silang rantai-rantai polimer sehingga membentuk suatu jala tiga dimensi bersambungan. Selanjutnya jala ini dapat menangkap atau mengimobilisasikan air di dalamnya sehingga dapat membentuk struktur yang kuat dan kaku. Bila dibandingkan dengan nilai kadar air permen jelly pembanding (komesial) yang memiliki nilai kadar air $13,81 \%$ maka nilai kadar air produk permen jelly ini relatif lebih tinggi. Hal ini disebabkan karena dalam proses pembuatan permen jelly ini membutuhkan jumlah air yang lebih banyak untuk melarutkan tepung karagenan karena bahan ini sukar larut dibandingkan dengan gelatin. Jika dibandingkan dengan dengan Standar Nasional Indonesia permen jelly, kadar air permen jelly hasil penelitian melibihi batas maksimal kadar air permen jelly sesuai dengan SNI (2008) yaitu sebesar 20\%.

Kadar abu

Tabel 4. Kadar Abu Permen Jelly Hasil Penelitian

\begin{tabular}{cc}
\hline Perlakuan & Kadar Abu \\
\hline A (Gelatin 8\% : Iota K. 0\%) & $0,63 \pm 0,03^{\mathrm{a}}$ \\
B (Gelatin 0\% : Iota K. 8\%) & $0,93 \pm 0,04^{\mathrm{b}}$ \\
C (Gelatin 6\% : Iota K. 2\%) & $1,05 \pm 0,05^{\mathrm{bc}}$ \\
D (Gelatin 2\%: Iota K. 6\%) & $1,12 \pm 0,08^{\mathrm{c}}$ \\
\hline
\end{tabular}

Nilai rata-rata kadar abu permen jelly berkisar antara $0,63-1,12 \%$. Kisaran nilai tersebut lebih tinggi $0,5 \%$ dari penelitian Wijana et al. (2014), tetapi masih memenuhi kriteria Standar Nasional Indonesia (2008) tentang kembang gula lunak. Syarat mutu kadar abu pada produk kembang gula lunak jelly maksimal 3,0\%. Bila dibandingkan dengan nilai kadar abu permen jelly pembanding (komesial) sebesar 1,64\% maka nilai kadar abu pembanding ini relatif lebih tinggi dari pada permen jelly hasil penelitian. Komposisi yang terkandung dalam permen jelly pembanding (komersial) yaitu sirup glukosa, gula, pati tapioka, gelatin, pengatur keasaman asam malat, ekstrak (jeruk, nanas, anggur, pisang, apel, stroberi), perisa (jeruk, nanas, anggur, pisang, apel, stroberi), pewarna (tartazin CI 19140, kuning FCF CI 15985, biru berlian CI 42090, merah alura CI 16035). Tingginya kadar abu permen jelly pembanding (komersial) diduga karena komposisi pembuatannya dan kandungan gelatin yang digunakan lebih dari $8 \%$. Kandungan mineral pada gelatin mencapai $2-4 \%$ (Hastuti dan Sumpe, 2007). Jumlah tersebut termasuk kategori yang cukup tinggi. Efek dari tingginya penambahan gelatin ke permen jelly mengakibatkan kadar abu permen jelly juga semakin meningkat. Demikian pula dengan peningkatan konsentrasi karagenan akan meningkatkan kadar abu. Karagenan juga mengandung mineral yaitu kalium, natrium,

() Copyright by Saintek Perikanan (Indonesian Journal of Fisheries Science and Technology), ISSN : 1858-4748 
kalsium dan magnesium (Diharmi et al., 2011). Penelitian Diharmi (2015), menunjukkan bahwa kandungan mineral karagenan dari rumput laut $E$. spinosum untuk kalium sebesar $5,05 \%$, natrium sebesar $0,6 \%$, magnesium sebesar $0,55 \%$ dan kalium sebesar 1,69\%, sehingga kombinasi antara gelatin dan iota karagenan dapat meningkatkan kadar abu.

\section{Gel strength}

Tabel 5. Gel Strength Permen Jelly Hasil Penelitian

\begin{tabular}{cr}
\hline Perlakuan & \multicolumn{1}{c}{ Gel Strength } \\
\hline A (Gelatin 8\% : Iota K. 0\%) & $6.773,90 \pm 313,90^{\mathrm{c}}$ \\
B (Gelatin 0\% : Iota K. 8\%) & $1.109,27 \pm 52,19^{\mathrm{b}}$ \\
C (Gelatin 6\%: Iota K. 2\%) & $1.061,79 \pm 23,19^{\mathrm{b}}$ \\
D (Gelatin 2\% : Iota K. 6\%) & $354,59 \pm 10,60^{\mathrm{a}}$ \\
\hline
\end{tabular}

Nilai gel strength permen jelly perlakuan B dan C lebih tinggi $0,7 \%$ dari gel strength tertinggi permen jelly hasil penelitian Sinurat dan Murniyati (2014), sedangkan gel strength terendah permen jelly perlakuan D lebih tinggi $0,9 \%$ dari gel strength terendah permen jelly Sinurat dan Murniyati (2014). Nilai gel strength tertinggi didapat pada perlakuan A yang menggunakan gelatin $8 \%$. Penggunaan gelatin ini membuat gel yang baik pada permen jelly dan nilai ini lebih tinggi dari nilai gel strength permen jelly pembanding (komersial) sebesar 3105,56 g.cm2. Menurut Nurismanto et al. (2015), semakin tinggi konsentrasi gelatin maka semakin tinggi kekuatan gel. Hal ini disebabkan karena gelatin mampu menghasilkan gel yang sangat baik, yaitu berkisar antara 5$12 \%$ tergantung dari kekerasan akhir dari produk yang diinginkan. Perbedaan yang tinggi untuk perlakuan D, dikarenakan pencampuran gelatin dan karagenan kurang sinergis dan membuat permen jelly tersebut sangat kental tetapi tidak dapat bersatu (mudah hancur). Karagenan merupakan bahan olahan rumput laut sering digunakan sebagai penstabil, pengemulsi, pembentuk gel pada produk pangan. Menurut Wijana et al. (2014), kombinasi kedua gelling agent ini menghasilkan tekstur yang bervariasi mengingat ciri khas karagenan dan gelatin yang berbeda dalam menghasilkan tekstur gel.

$\mathrm{pH}$

Tabel 6. pH Permen Jelly Hasil Peneltian

\begin{tabular}{cc}
\hline Perlakuan & pH \\
\hline A (Gelatin 8\% : Iota K. 0\%) & $4,36 \pm 0,03^{\mathrm{d}}$ \\
B (Gelatin 0\%: Iota K. 8\%) & $3,59 \pm 0,05^{\mathrm{a}}$ \\
C (Gelatin 6\%: Iota K. 2\%) & $4,26 \pm 0,02^{\mathrm{c}}$ \\
D (Gelatin 2\%: Iota K. 6\%) & $3,87 \pm 0,02^{\mathrm{b}}$ \\
\hline
\end{tabular}

Nilai $\mathrm{pH}$ yang dihasilkan tergolong dalam kondisi asam karena nilai $\mathrm{pH}$ berada di bawah 7 (netral). Kondisi asam ini disebabkan karena adanya penambahan asam sitrat, namun jumlah asam sitrat yang ditambahkan pada setiap perlakuan adalah sama yaitu sebesar $0,8 \%$. Bila dibandingkan dengan $\mathrm{pH}$ permen jelly pembanding (komersial) yaitu 3,55, nilainya lebih rendah dari pada permen jelly hasil penelitian. Menurut Koswara (2009), keberhasilan pembuatan jelly tergantung dari derajat keasaman untuk mendapatkan $\mathrm{pH}$ yang diperlukan. Nilai $\mathrm{pH}$ dapat diturunkan dengan penambahan sejumlah kecil asam sitrat. Penambahan asam sitrat dalam permen jelly beragam tergantung dari bahan baku pembentuk gel yang digunakan. Hal ini diperkuat juga oleh Muawanah et al. (2012), penambahan asam sitrat selain menambah rasa, juga akan menurunkan $\mathrm{pH}$. $\mathrm{pH}$ yang asam akan menghambat pertumbuhan mikroba pembusuk sehingga permen jelly memiliki daya awet relatif tinggi.

$\mathrm{a}_{\mathrm{w}}$

Tabel 7. $\mathrm{a}_{\mathrm{w}}$ Permen Jelly Hasil Penelitian

\begin{tabular}{lc}
\hline \multicolumn{1}{c}{ Perlakuan } & \multicolumn{1}{c}{$\mathbf{a w}_{\mathrm{w}}$} \\
\hline A (Gelatin 8\%) & $0,84 \pm 0,01^{\mathrm{a}}$ \\
B (Iota Karagenan 8\%) & $0,86 \pm 0,01^{\mathrm{b}}$ \\
C (Gelatin 6\% : Iota K. 2\%) & $0,89 \pm 0,01^{\mathrm{c}}$ \\
D (Gelatin 2\% : Iota K. 6\%) & $0,87 \pm 0,01^{\mathrm{b}}$ \\
\hline \multicolumn{2}{l}{ Hasil pengamatan nilai aw permen jelly menunjukkan }
\end{tabular}
bahwa produk tersebut memiliki aw kisaran 0,84 - 0,89. Nilai tersebut sangat tinggi untuk penyimpanan produk, mengingat bakteri dan kapang umumnya bisa hidup pada produk yang memiliki nilai aw 0,7 atau lebih tinggi. Bila dibandingkan dengan permen jelly pembanding (komersial) dengan aw 0,70, aw permen jelly hasil penelitian lebih tinggi. Tingginya nilai aw dikarenakan kadar air dalam produk permen jelly yang dihasilkan lebih tinggi $100 \%$ dari SNI (2008). Nilai kadar aw permen jelly hasil penelitian lebih tinggi dari pada nilai aw permen jelly menurut Sinurat dan Murniyati (2014) yaitu tertinggi sebesar 0,80, sedangkan terendah sebesar 0,71. Menurut Soekarto (1979) dalam Salamah et al. (2006), makanan semi basah mempunyai nilai aw antara 0,6-0,9 akan cukup awet dan stabil pada penyimpanan suhu kamar dan aw pada permen jelly rumput laut berada dalam selang aw untuk produk pangan semi basah. Menurut Winarno (1992), aktivitas air (aw) merupakan parameter yang menunjukkan besarnya air bebas dalam suatu produk, yang memungkinkan bagi mikroorganisme untuk hidup. Semakin kecil nilai aw suatu produk maka daya simpan produk tersebut semakin lama karena mikroorganisme dan kapang hanya bisa hidup pada kondisi aw tertentu. Aktivitas air minimum untuk pertumbuhan bakteri dan kapang adalah 0,7 .

Karakteristik Mikrobiologi (Pengujian Kapang) Tabel 8. Pengujian Kapang Permen Jelly Hasil Penelitian

\begin{tabular}{cccc}
\hline \multirow{2}{*}{ Perlakuan } & \multicolumn{3}{c}{$\begin{array}{c}\text { Lama Penyimpanan } \\
\text { (koloni/gram) }\end{array}$} \\
\cline { 2 - 4 } & $\begin{array}{c}\text { 0 } \\
\text { hari }\end{array}$ & 10 hari & 20 hari \\
\hline A (Gelatin 8\% : Iota K. 0\%) & 0 & $10^{1}$ & $5 \times 10^{1}$ \\
B (Gelatin 0\% : Iota K. 8\%) & 0 & 0 & $1,2 \times 10^{2}$ \\
C (Gelatin 6\%: Iota K. 2\%) & 0 & 0 & $1,2 \times 10^{2}$ \\
D (Gelatin 2\% : Iota K. 6\%) & 0 & 0 & $2,0 \times 10^{2}$ \\
\hline
\end{tabular}

Pengujian kapang dilakukan untuk mengetahui daya simpan produk. Daya simpan permen jelly ini dipengaruhi oleh beberapa hal seperti fisik/kimia produk, kemasan dan lingkungan. Pengujian kapang dilakukan dengan menghitung koloni pertumbuhan kapang pada permen jelly. Berdasarkan hasil penelitian, penyimpanan 0 hari terhadap kelima perlakuan permen jelly tidak didapatkan pertumbuhan kapang, sedangan pada penyimpanan 10 hari sudah tumbuh kapang pada permen jelly A sebanyak $10^{1} \mathrm{koloni} / g r a m$. Hal tersebut sesuai dengan pernyataan Yustina dan Antarlina (2013) yang mengatakan bahwa pertumbuhan kapang mulai terjadi pada penyimpanan hari ke-10. Batas pertumbuhan kapang menurut Badan Standarisasi Nasional (2008) maksimal $1 \times 10^{2}$ koloni/gram. Apabila dibandingkan dengan BSN (2008), penyimpanan selama 20 hari menunjukkan bahwa permen jelly A masih dibawah standar pertumbuhan kapang, sedangkan permen jelly $\mathrm{B}, \mathrm{C}$, dan D diatas standar pertumbuhan kapang.

\footnotetext{
(C) Copyright by Saintek Perikanan (Indonesian Journal of Fisheries Science and Technology), ISSN : 1858-4748
} 
Hedonik

Berdasarkan data hasil uji hedonik, diketahui bahwa kelima perlakuan dalam penelitian pembuatan permen jelly dengan penambahan tepung iota karagenan dari rumput laut $E$. spinosum disukai oleh konsumen. Hal tersebut dibuktikan dengan hasil nilai overall acceptance dari permen jelly tersebut sebesar $7 \leq \leq 8$ dari skala $1-9$. Hasil yang diperoleh dari uji hedonik permen jelly hasil penelitian dapat dilihat pada Tabel 9. Pada selang kepercayaan $95 \%$, perlakuan A memiliki nilai 8 yang artinya amat disukai oleh konsumen, sedangkan perlakuan B, C, D nilai tertinggi didapatkan pada perlakuan B yaitu 7 yang artinya disukai oleh konsumen.

Tabel 9. Nilai Hedonik Permen Jelly Hasil Penelitian

\begin{tabular}{cc}
\hline Perlakan & Selang Kepercaan \\
\hline A (Gelatin 8\%: Iota K. 0\%) & $7,98 \leq \mu \leq 8,42$ \\
B (Gelatin 0\%: Iota K. 8\%) & $6,84 \leq \mu \leq 7,52$ \\
C (Gelatin 6\%: Iota K. 2\%) & $6,37 \leq \mu \leq 7,03$ \\
D (Gelatin 2\%: Iota K. 6\%) & $6,59 \leq \mu \leq 7,21$ \\
\hline
\end{tabular}

\section{KESIMPULAN}

Nilai hasil gel strength untuk perlakuan B (Gelatin 0\%: Iota K. 8\%) lebih tinggi dari pada C (Gelatin 6\% : Iota K. 2\%) dan D (Gelatin 2\% : Iota K. 6\%) dan ketiga perlakuan itu belum melebihi nilai pembanding A (gelatin $8 \%$ ) dan permen jelly komersial. Untuk kadar air ketiga perlakuan belum memenuhi standar SNI. Kadar abu memenuhi standar SNI untuk ketiga perlakuan, aw dan $\mathrm{pH}$ memenuhi standar permen jelly. Berdasarkan hasil hedonik terbaik sebagai alternatif pengganti gelatin yaitu perlakuan B (Iota K. 8\%) sebesar 6,84 $\leq \leq 7,52$.

\section{UCAPAN TERIMA KASIH}

Penulis mengucapkan terima kasih kepada Bapak Dr. Ir. W. Farid Ma'ruf, M.Sc atas masukan dan saran terhadap penelitian ini.

\section{DAFTAR PUSTAKA}

AOAC Internasional. 1999. Official Method of Analysis 925.45. Http://www.aoac.org (Tanggal akses: 25 September 2011).

Asikin, A. N., I. Kusumaningrum dan D. Sutono. 2015. Ekstraksi dan Karakterisasi Sifat Fungsional Karaginan Kappaphycus alvarezii Asal Pesisir Kabupaten Kutai Timur. Jurnal Ilmu dan Teknologi Kelautan Tropis. 7(1) : 49-58.

Atmaka, W., E. Nurhartadi, dan M. M. Karim. 2013. Pengaruh Penggunaan Campuran Karagenan dan Konjak Terhadap Karakterisik Permen Jelly Temulawak (Curcuma xanthorrhiza Roxb.). Jurnal Teknosains Pangan, 2 (2). ISSN: 2302-0733.
[BSN] Badan Standardisasi Nasional. 2004. SNI 06-6989.202004 Air dan air limbah-Bagian 20: Cara uji sulfat. Jakarta: Badan Standardisasi Nasional.

[BSN] Badan Standardisasi Nasional. 2008. SNI 3547.2.2008 Kembang Gula-Bagian 2: Lunak. Jakarta: Badan Standardisasi Nasional.

Darmawan, M., R. Peranginangin, R. Syarief, I. Kusumaningrum, dan D. Fransiska. 2014. Pengaruh Penambahan Karaginan untuk Formulasi Tepung Puding Instan. JPB Perikanan. 9(1) : 83-95.

Diharmi, A., D. Fardiaz, N. Andarwulan, dan E. S. Heruwati. 2011. Karakteristik Karagenan Hasil Isolasi Euchema spinosum (Alga Merah) dari Perairan Semenep Madura. Jurnal Perikanan dan Kelautan. 16(1):117-124.SNI (2004)

Diharmi, A. 2015. Komposisi Kimia dan Mineral Rumput Laut Eucheuma spinosum Kering dari Perairan Nusa Penida, Sumenep, dan Takalar. Dalam : Seminar Nasional MPHI di Bogor Tanggal 23-24 Oktober 2015.

Hastuti, D., dan I. Sumpe. 2007. Pengenalan dan Proses Pembuatan Gelatin. Jurnal ilmu-ilmu pertanian.

Koswara, S. 2009. Teknologi Pembuatan Permen. Ebookpangan.com

Maitimu, V., A. M. Legowo, dan A. N. Al-Baarri. 2012. Parameter Keasaman Susu Pasteurisasi dengan Penambahan Ekstrak Daun Aileru (Wrightia caligria). Jurnal Aplikasi Teknologi Pangan. 1(1).

Muawanah, A., I. Djajanegara, A. Sa'duddin, D. Sukandar, dan N. Radiastuti. 2012. Penggunaan Bunga Kecombrang (Etlingera elatior) dalam Proses Formulasi Permen Jelly. Valensi. 2(4) : 526-533. ISSN : 1978 - 8193.

Nurismianto, R. Sudaryati, dan A. H. Ihsan. 2015. Konsentrasi Gelatin dan Karagenan pada Pembuatan Permen Jelly Sari Brokoli (Brassica oleracea). Jurnal Rekapangan. 9(2).

Rahmawati, A., B. Kuswandi, dan Y. Retnaningtyas. 2015. Deteksi Gelatin Babi pada Sampel permen Lunak Jelly Menggunakan Metode Fourier Tranform Infra Red (FTIR) dan Kemometrik. E-jurnal Pustaka Kesehatan. $3(2)$.

Rahmi, S. L., F. Tafzi, dan S. Anggraini. 2014. Pengaruh Penambahan Gelatin Terhadap Pembuatan Permen Jelly

(ㄷ) Copyright by Saintek Perikanan (Indonesian Journal of Fisheries Science and Technology), ISSN : 1858-4748 
dari Bunga Rosella (Hibiscus sabdariffa Linn). Jurnal Penelitian Universitas Jambi Seri Sains. 14(1) : 37-44. ISSN 0852-8349.

Salamah, E., A. C. Erungan, dan Y. Retnowati. 2006. Pemanfaatan Gracilaria Sp. Dalam Pembuatan Permen Jelly. Buletin Teknologi Hasil Perikanan. 9(1).

Shimizu, Y., Toyohara H, Lanier TC. 1992. Surimi production from fatty and dark-fleshed fish species, in Surimi Technology (eds T.C Lanier and C.M Lee), Marcel Dekker York, pp. 181-207.

Sinurat, E. dan Murniyati. 2014. Pengaruh Waktu dan Suhu Pengeringan Terhadap Kualitas Permen Jeli. JPB Perikanan. Vol 9 (2): 133-142.

Suptijah, P., S. H. Suseno, dan C. Anwar. 2013. Analisis Kekuatan Gel (Gel Strength) Produk Permen Jelly dari Gelatin Kulit Ikan Cucut Dengan Penambahan Karagenan dan Rumput Laut. JPHPI. 16(2).
Wijana, S., A. F. Mulyadi, dan T. D. T. Septivirta. 2014. Pembuatan Permen Jelly Dari Buah Nanas (Ananas Comosus L.) Subgrade (Kajian Konsentrasi Karagenan Dan Gelatin). Universitas Brawijaya.

Winarno, F.G., Fardiaz, S. dan Fardiaz, D. 1992. Pengantar Teknologi Pangan. PT. Gramedia. Jakarta.

Yasita, D. dan I. D. Rachmawati. 2009. Optimasi Proses Ekstraksi Pada Pembuatan Karagenan dari Rumput Laut Eucheuma cottoni untuk Mencapai Foodgrade. Jurusan Teknik Kimia Fakultas Teknik Universitas Diponegoro.

Yustina, I., dan SS. Antarlina. 2013. Pengemasan dan Daya Simpan Permen Nanas. Seminar Nasional : Menggagas Kebangkitan Komoditas Unggulan Lokal Pertanian dan Kelautan Fakultas Pertanian Universitas Trunojoyo Madura. 